\title{
Material Flow Cost Accounting System for Decision Making: The Case of Taiwan SME in the Metal Processing Industry
}

\author{
Shen-Ho Chang \\ Department of Accounting and Centre for Environmental Accounting Research, Feng Chia \\ University
}

No. 100, Wenhwa Rd., Seatwen, Taichung, Taiwan 40724

E-mail: shchang@fcu.edu.tw

An-An Chiu (Corresponding author)

Bachelor's Program of International Business Administration, Feng Chia University

No. 100, Wenhwa Rd., Seatwen, Taichung, Taiwan 40724

E-mail: ananchiu2009@gmail.com

\section{Chin Ling Chu}

Department of International Logistics and Marketing Management, Tatung Institute of Commerce and Technology

and

Ph.D. Program in Business, Feng Chia University

No. 100, Wenhwa Rd., Seatwen, Taichung, Taiwan 40724

E-mail: chinling@ms2.ttc.edu.tw

Teng-Shih Wang

Ph.D. Program in Business, Feng Chia University

No. 100, Wenhwa Rd., Seatwen, Taichung, Taiwan 40724

E-mail: t.swang0617@gmail.com 


\author{
Teng-Shih Wang \\ Administrator, Division of Finance, \\ Taoyuan Metro Corporation, Taiwan \\ No.251, Sec. 4, Linghang N. Rd., Taoyuan City 337, Taiwan \\ E-mail: t.swang0617@gmail.com
}

\begin{abstract}
Sung-I Hsieh
Budget, Accounting and Statistics Department, Taitung County Government, Taiwan and
\end{abstract}

Ph.D. Program in Business, Feng Chia University

No. 100, Wenhwa Rd., Seatwen, Taichung, Taiwan 40724

E-mail: aa0110913@gmail.com

Received: Jan. 31, 2015 Accepted: March 22, $2015 \quad$ Published: June 1, 2015

doi:10.5296/ajfa.v7i1.7033 URL: http://dx.doi.org/10.5296/ajfa.v7i1.7033

\begin{abstract}
The purpose of this paper is to examine the implementation of a Material Flow Cost Accounting system (MFCA) and to provide meaningful results for managers to make decision. A case study and the depth interview were employed for small- and medium-size enterprises in the metal processing industry to collect the information for further analysis. The result shows that the implementation of the Material Flow Cost Accounting system can mitigate the probability of dysfunctional decision making, particularly for investment decisions, assist managers in directly filtering out energy or material waste, and enhance the accuracy of product cost evaluations. This paper concludes that the Material Flow Cost Accounting system is not only a management tool, which helps managers achieve cost reductions, but also a mechanism, which realize corporate social responsibility. The results of this investigation support the proposition that implementation of environmental collaboration and monitoring practices by supply chain partners are both environmentally necessary and good business. The paper provides manufacturing managers with a structured approach to improving both environmental and organizational performance through environmental collaboration and monitoring with customers and suppliers
\end{abstract}

Keywords: Material Flow Cost Accounting System, Corporate Social Responsibility, Decision Making 


\section{Introduction}

Environmental problems caused by economic growth have become worse and, as a result, the disclosure of social and environmental information has been increasing in popularity and acceptance among business entities, academics, and practitioners (Djajadikerta and Trireksani, 2012). As both internal and external pressures build to force corporations to adopt and maintain environmentally friendly processes and to produce environmentally friendly products and services, manufacturers must consider implementing the information system to improve the business performance and the economic viability of the corporations, as well as the environmental performance of the corporations (Elliot, 2011; Green et al., 2012).

Material flow cost accounting is essential instrument in a management approach know as flow management (Strobel, 2001). The aim of flow management is to improve the management of production companies by overcoming compartmental thinking and instead to see one's organization as a system that channels and transforms flows of materials and information from beginning to end. Flow management, with the goal of having a company that is profitable and environmentally sound

Governments around the world have committed themselves to environmental protection to prevent further environmental deterioration and solve existing environmental problems. Since 2002, the Taiwanese government has motivated the study of environmental accounting plans and assisted in the trial of these plans. In addition, the government has promoted the introduction and implementation of environmental accounting systems, in particular the implementation of a material flow cost accounting system. In 2013, InnoLux was awarded the first ISO14051 Material Flow Cost Accounting (MFCA) certificate in the world for identifying, through the implementation of MFCA, the waste accrued during manufacturing processes and improving operating processes to increase corporate profits. InnoLux has validated that the MFCA is not only a decision-making tool, but also an instrument to assist corporations in undertaking their social responsibilities. In comparison with large enterprises like InnoLux, small- and medium-size enterprises have their own reasons to implement MFCA. As $97 \%$ of the corporations in Taiwan are small- and medium-size, they have limited resources to engage in environmental protection activities. However, the enhancement of environmental performance can be significant if these corporations are guided to establish and implement MCFA.

Other than inputting additional resources to comply with increasingly strict environmental laws, small- and medium-size enterprises compete for their profit in this competitive market either by increasing revenues or by reducing costs. It is easier and less risk to reduce a dollar of cost than to increase a dollar of revenue. Therefore, locating and improving operational weaknesses and, thereby, enhancing financial and environmental performance after establishing MFCA is an important topic for small- and medium-size enterprises. The introduction of MFCA to companies has indeed achieved simultaneous benefits of economic gains and environmental sustainability (Sulong et al., 2014). This paper proposes a case study of the small- and medium-size enterprise in the metal processing industry that adopts MFCA to assist managers to make decisions and reduce costs and environmental impact. 
The metal processing industry ${ }^{1}$, including hand tools, nuts, bolts, screws and other metal manufacturing and surface treatments, is indispensable to Taiwan's supply chain. The manufacturing of bolts and screws requires wire rod treatment, which involves the utilization of greater resources, such as power and material loss, and environmental pollution. The treatment includes a few processes: continuous drawing of wire rods, as well as spheroidizing and phosphating wire rods. The rusty part of wire rods is eliminated and the rest of the wire rods are initially processed during the drawing process. The spheroidizing process enhances the stiffness and toughness of the wire rods by using heat treatment that consumes large amounts of electricity and generates considerable amounts of heat waste. The phosphating process involves cleaning impurities off the surface of the wire rods and soaking them in materials that form a protective membrane ${ }^{2}$ that prevents rusting. This process consumes a large amount of water and produces sewage. The continuous drawing process cleans chemical powder off the surface of the wire rods, and consumes large amounts of electricity. To conclude, the consumption of electricity and water resources increases the cost of products and causes heavy metal contamination, which results in heavy fines.

Fakoya and van der Poll (2013) note that material flow cost accounting can identify the material losses that traditional standard cost accounting cannot recognize, such as, waste or non-product outputs. Under the traditional cost accounting, activity-based costing or time-oriented activity-based costing systems, wastes are viewed as no value because they are considered irrelevant to the value chain. The importance of waste is ignored as one of the outputs of operational processes. However, in MFCA, the value of waste is not an allowance for product costs. Instead, it should be assessed with the same valuation as the product such as using physical information as the basis of cost calculation. Product costs (positive product costs) or losses (negative product costs) are calculated on the same basis (Nakajima, 2004, 2009). MFCA can identify and analyze the value of waste, which assists organizations to know the role of waste in the value chain (Möller and Prox, 2008).

By implementing and analyzing MCFA, this study discovers that waste in water resources is the main improvement decision that the case company needs to make. Three additional problems including output of defective goods, residue recovery, and the heat waste are caused by the phosphating process. Apart from waste in water resources, we find that the materials used in defective goods can be reused to make new products and sold to customers at the original price. Managers may think that the additional costs of remaking defective goods are insignificant. However, this study shows that, the negative costs incurred at the end of the operation are greater than the defective goods produced at the front operation. Moreover, the company can dry the residue using waste heat recycled from the manufacturing process

\footnotetext{
${ }^{1}$ According to data from MII-IT IS, the gross outputs of metal products in Taiwan in 2010 and 2011 are NTD 673,500,000 and NTD 754,300,000, respectively, among which bolts and screws account for NTD 109,800,000 and NTD 144,800,000, respectively.

2 There are nine processes involved in the phosphating process: material requisition, phosphating, water rinsing (1), oxalic acid neutralization, coating, water rinsing (2), water rinsing (3), lubrication, drying/inbound. First, wire rods are delivered to the entrance of the phosphating area (material requisition process) according to work orders. They are soaked in hydrochloric acid heated by fuel oil to remove the oxide film (phosphating process) and are washed with clean water (water rinsing 1). After that, they are processed with oxalic acid neutralization in order to make sure that the film is even when formed. The next step is coating, which involves soaking the wire rods in phosphate. After cleaning the precipitation on the surface using water (water rinsing process 2 ) and water rinsing process
} 
before the residue is recovered, to greatly reduce the cost of residue recovery management. Hence, managers may make dysfunctional decisions if these decisions are made based on intuition. With the use and assessment of quantitative information, this paper suggests that the case company should consider setting up inspection checkpoints and using waste heat rather than water reclamation for drying residue.

\section{Literature Review}

Material flow analysis assesses the effectiveness of material use to identify the waste produced from certain resources and materials (European Communities, 2001). Brunne and Rechberger (2005) define material flow analysis as a systematic assessment conducted on material flow and stocks within a system range, and defined time and space exigencies. Material flow analysis connects material source, path and final location. Due to the law of conservation of matter, material flow analysis can be controlled by comparing the analysis results of input, stock and output of material flow in operation. Hence, material flow analysis discusses the flows and stocks of materials. Material flow analysis can also be an assisting tool for decision making in resources management, waste management and environmental management. However, while material flow analysis only focuses on the research and analysis of physical units, monetary information is an important factor of management decision making.

Since material flow analysis lacks monetary information, while traditional cost accounting only focuses on currency information, Bernd Wagner of the University of Augsburg in Germany propose "Material Flow Cost Accounting" and "Flow Cost Accounting" to solve the above problems. Hargroves and Smith (2012) note that not only can MFCA provide physical information concerning material flow analysis, but also combine physical information with monetary information. Managers can clearly define ineffective production during the production process. Additional benefits include the material balance concept in material analysis, a new perspective on activity-based costing systems, cost accumulation and the calculation of positive/negative outputs.

Nakajima (2004) indicates that the production process in traditional cost accounting is a consumption process of economic values because the economic values of the consumed resources are added to the products, i.e. the products take on the costs of resources used. As a result, if a firm adopts the traditional cost accounting, then we can ignore important losses and obtain the product's costs. On the contrary, MFCA is a calculation method based on the concept of material balance, which allows the positive and negative product costs in each manufacturing process to be presented. Hence, managers are aware of material loss costs and low efficiency (Nakajima, 2004; ISO 14051, 2011). The most important advantage of MFCA is the transparency of costs to organizations.

ISO 14051 (2011) proposes that enterprises may ignore the importance of waste because it can be recycled and reused. In the past, waste from spoilage was not valued because it only needed to be remade as new finished goods and sold to downstream companies at the same price. According to MFCA, spoilage should be treated as a negative product and the cost of remaking spoiled products should be considered a negative cost. Hence, MFCA can present 
these costs to management to assist them understanding the cost of spoilage. MFCA assists managers to value waste and endeavor to reduce waste, which helps to improve the efficiency of production and reduce costs (Onishi, Kokubu and Nakajima, 2009).

As per the Material Flow Cost Accounting Guidelines of Japan (JMETI, 2007), the main purposes of MCFA are to reduce the costs and environmental impacts caused by corporate activities and to serve as a decision-making tool for corporations and managers. In fact, MCFA extends the main concept of material flow analysis and material flow accounting, namely "material balance", which means that input is equal to output. In MCFA, input includes all the resources needed for the manufacturing process; including primary raw materials, secondary raw materials, materials, direct labor, indirect labor, water, electricity, machinery, etc. Output is classified as positive product output ${ }^{3}$ and negative product output. Positive products are semi-finished goods in process, or finished goods; negative products are waste resources or recycled materials. In order to convert production into monetary units, input costs must be equal to product costs. This means that the total input costs are equal to positive product costs plus negative product costs (JMETI, 2007).

\section{Methodology and Sampling}

\subsection{Methodology}

This paper uses a case study and depth interviews following Fakoya and van der Poll (2013). Chetty (1996) indicates that exploratory research is the most common method used for case studies. The main purpose of this study is to use MFCA to assist managers in decision making to save costs. We believe that the case study method can further distinguish between the methods and steps involved in implementing an MFCA system and the influence of the information generated from the system on managers' daily decision making. In addition, in-depth interviews are employed in this study to gather information. Stacks (2010) points out that in-depth interviews can provide researchers with detailed backgrounds and assist researchers to understand both the researcher's and corporate managers' opinions of events. Considering that material flow cost accounting is established in the corporation's operational processes, this study believes that depth interviews assist in understanding the background, operational processes and current problems encountered by the case company.

\subsection{Selection of Case Company and Explanations}

The purpose of this paper is to discuss whether small- or medium-size enterprises in Taiwan are able to implement MCFA, and whether the results calculated by this system can present the product's costs or potential improvements more accurately to assist managers in making decisions. Moreover, we aim to establish feasible standard operating procedures for implementing MFCA in small- and medium-size enterprises. This paper selects a case company based on the following criteria:

1. Small and medium enterprises: According to the statistics, $97 \%$ of enterprises in Taiwan are small- or medium-size which shows that these enterprises hold a considerable position in

\footnotetext{
"Positive product output" and "negative product output" are the terms of JMETI. According to IFAC (2005), products are classified as "product output" and "non-product output", but the meanings for both are similar.
} 
the Taiwanese economy. This study chooses to implement the system in a small- or medium-size enterprise and expects that our results are applicable for most small- and medium-size enterprises.

2. Industry: Nakajima (2006) indicates that MFCA is more suitable for the processing industry and in particular for the manufacturing process of parts of materials and the assembly process. Hence, this study chose the processing industry, which has higher productivity and implementing benefits.

Our case company is a medium-sized metal processing company. In the past, the organization mainly used standard manufacturing costing, the cost control tool. However, the manager still did not understand the actual cost of a product and thought that he or she could not effectively use water resources, which is a heavy burden on the company's finance. Hence, the company urgently needs to improve its recycling of water resources. The working hours for the batch production line are eight hours per day. The major raw materials of the company are wire rods. These are produced as finished products through four processes: the drawing process, spheroidizing process, phosphating process and continuous drawing process (as shown in Fig. 1). Wire rods become semi-finished goods after the drawing process. These semi-finished goods then go through the spheroidizing process and the phosphating process. Wire rods are completed as finished goods during the continuous drawing process.

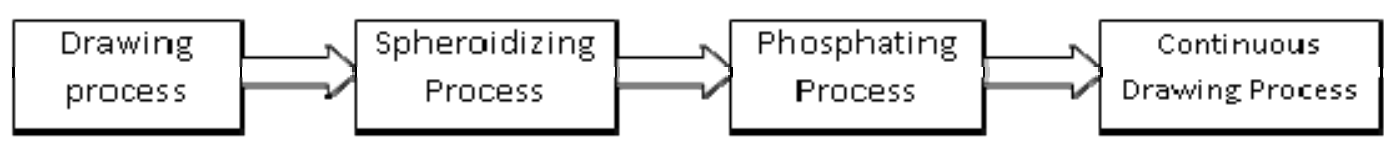

Figure 1. Complete operating processes of the case company

The case company employed a traditional cost accounting system to calculate costs and understand its past performance. However, the weakness of the traditional cost accounting system is that it only uses the single basis without taking into consideration either environmental costs or benefits. After an in-depth interview with the general manager, we discovered that the primary source of waste is the running water used during the phosphating process. Although some of this water can be reclaimed and reused, the rest of it must be emitted to the sewage treatment plant in the industrial area through the company's sewage treatment equipment. Given this, management believes that it can save a lot on costs if water can be recycled more effectively.

However, from the point of view of MFCA, the recycling of water is not the only waste produced by the company. There are other inevitable losses which are considered as waste, such as the input of losses of resources in the drawing process and continuous drawing process for remaking products. Furthermore, materials and energy are necessary for the production and maintenance of operations. If we can reduce product inputs and the wasting of resources caused by remaking products, this would result in great benefits to the company. 


\section{Macrothink}

Given this, this paper, using MFCA, recalculates product costs among operating processes, discusses water waste and discovers the greatest sources of waste as well as potential improvements.

\section{Analysis of Effectiveness of Implementing Material Flow Cost Accounting}

There are seven steps involved in establishing MFCA including planning, collection and compiling of data, material flow cost accounting calculation, confirming improvements, planning improvement projects, executing improvements and assessing improvement effects (JMETI, 2007). Chen and Ko (2005) indicate that the development of an accounting system includes planning, analysis, design, execution, and feedback. Hence, this paper establishes and analyzes MFCA in three major steps: planning, execution, and improvements and feedback.

\subsection{Planning}

Based on JMETI (2007), planning covers four phases: determining goals ${ }^{4}$, determining quantity centers ${ }^{5}$, determining the analysis for each period and determining the methods. Table 1 shows the summary of the planning steps:

\footnotetext{
${ }^{4}$ This means analyzing which goal is the most appropriate and has top priority in order to establish material flow cost accounting. A goal can be a product, a production line or even the important or major production process of a series of related products.

${ }^{5}$ This is primarily determined by analyzing goals and handling future situations. ISO 14051 defines a quantity center as a selected single process or a set of processes to quantify physical and currency unit inputs and outputs. Hence, each process can be treated as a quantity center, such as material requisition, cutting, cleaning, inspection, packing, delivery and storage areas. A quantity centre is normally determined by waste processes, so quantity centers are normally more that process centers.
} 
Table 1. Planning-Case Company

\begin{tabular}{|c|c|c|}
\hline Phases & Step & Case company \\
\hline \multirow{4}{*}{ 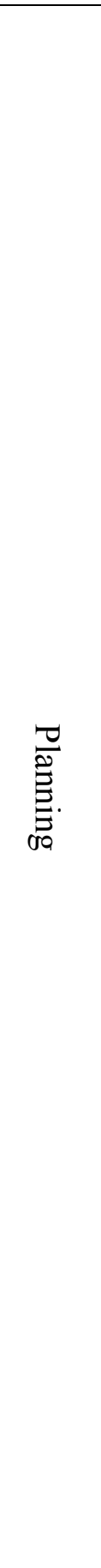 } & $\begin{array}{l}\text { Determine } \\
\text { goals }\end{array}$ & $\begin{array}{l}\text { 1. The nature of the case company is mass production. All } \\
\text { products go through the same manufacturing processes. So } \\
\text { we decided to use the manufacturing processes as our goal, } \\
\text { which includes the drawing process, spheroidizing process, } \\
\text { phosphating process and continuous drawing process. }\end{array}$ \\
\hline & $\begin{array}{l}\text { Determine } \\
\text { quantity } \\
\text { center }\end{array}$ & $\begin{array}{l}\text { 1. Before determining the quantity center, it is necessary for } \\
\text { researchers to understand the manufacturing processes of } \\
\text { the case company. This can be done by collecting the } \\
\text { operating procedures standard. In this paper, we adequately } \\
\text { comprehend this information via the process control } \\
\text { enactment. } \\
\text { 2. Although four operating centers in the case company can be } \\
\text { further classified into different groups (e.g. phosphating } \\
\text { process can be divided into smaller operations), } \\
\text { considering that this is the first time to establish MFCA, } \\
\text { information, including information about cost benefits, is } \\
\text { not easily gathered }{ }^{6} \text {, and so we expect to establish four } \\
\text { operating centers as quantity centers. We will determine } \\
\text { the sub-operations if more precise information is required } \\
\text { after the initial implementation and understanding of the } \\
\text { positive/negative cost overview of the company. If this is } \\
\text { the case, then we either execute again or the case company } \\
\text { itself will establish quantity centers based on smaller } \\
\text { operations. }\end{array}$ \\
\hline & $\begin{array}{l}\text { Determine } \\
\text { analysis } \\
\text { model and } \\
\text { period }\end{array}$ & $\begin{array}{l}\text { 1. It is the first time for the case company to establish material } \\
\text { flow accounting of environmental management accounting, } \\
\text { so the analysis period should not be too long, in order to } \\
\text { reduce the difficulty of initial implementation and the risk } \\
\text { of failure. When Nitto Denko Co., Ltd. established MFCA } \\
\text { for the first time, the analysis period was a month. Hence, } \\
\text { this paper expects that the analysis period is a month with a } \\
\text { three-month range from Oct } 2010 \text { to Dec } 2010 \text {. }\end{array}$ \\
\hline & $\begin{array}{l}\text { Determine } \\
\text { method of } \\
\text { collecting } \\
\text { data }\end{array}$ & $\begin{array}{l}\text { 1. To reduce the difficulty for initial establishment and } \\
\text { enhance benefits, we expect to be provided with } \\
\text { accounting information by the case company. } \\
\text { 2. If we lack the necessary data for establishing material flow } \\
\text { cost accounting, then we will ask the case company to } \\
\text { collect these data again. }\end{array}$ \\
\hline
\end{tabular}

\subsection{Execution}

According to JMETI (2007), execution covers two stages: the collecting and compiling of data and the calculation of material flow cost accounting. Material flow cost accounting

\footnotetext{
${ }^{6}$ We have discussed this with the management who are involved in material flow cost accounting. The costs and quantity data of the company were recorded at the process level. If we divide the phosphating process into smaller processes, then all of the information has to be recollected, which might not be cost effective. Given this, we set up a quantity center at the process level in order to reduce implementation costs.
} 
builds quantity centers by processes and obtains cost information by physical quantity as the basis of the calculation. This calculation method facilitates the combination of both costs and benefits. The differences with general accounting systems include the requirements of costing information of raw materials, labor, manufacturing costs and the physical information of raw materials. Physical information can be difficult to collect because a company may not have this information or because it is not willing to disclose relevant information. As a result, this is believed to be the most difficult step in the MFCA. This paper overcomes this problem by communicating and coordinating with the manager in the case company.

Data collection is used to quantify the quantities of input and output against each quantity center based on material balance, and to collect the relevant costs for each quantity center, including material costs, energy costs, system costs and waste treatment costs. Material costs can be direct, but energy costs and system costs are amortized into quantity centers and then amortized into positive or negative products from each quantity center. With regard to the amortization of energy costs and system costs, both JMETI (2007) and ISO 14051 (2011) indicate that amortization can be based on the positive/negative proportion of materials.

The second stage of calculation depends on the information gathered and the concept of material balance used in MFCA theory. This stage can be divided into three stages: a complete calculation of physical quantity units ${ }^{7}$; a complete calculation of currency quantity units; and completing the input/output relationship of positive products among quantity centers by inter-process integration ${ }^{8}$, adjustment and completion of the costing table as shown in Table 2. We can learn from Table 2 that the total cost of positive products in the drawing process center, spheroidizing process center, phosphating process center and continuous drawing process center are 25,138,480, 25,138,480, 25,049,479 and 25,113,300, respectively. While the total cost of negative products in these process centers are 614,176 , $35,060,355,293$ and 140,788, respectively. We can then determine that negative materials total costs are generated mostly in the drawing process center and the phosphating process center.

In addition, there are waste management costs which are not listed in Table 2 . These costs are generated from the management of sewage from the phosphating process center. The sewage treatment equipment in the company has already exceeded its service life, and there is no depreciation cost whatsoever. The waste management costs will only include current sewage treatment charges and residue disposal charges with an actual amount of $\$ 68,320$ (non-standard output) on average within 3 months. The contract price for residue disposal is $\$ 55,000$ per month, but the management of the company mentioned that the treatment company is willing to handle this process for free if the residue is dry enough.

\footnotetext{
7 This paper consults the method suggested by JMETI (2007) to convert all inconsistent units into kilograms. The conversion method is to multiply kilogram with density.

${ }^{8}$ The application of inter-process integration factors can solve the problem of values transferred out not matching with values transferred in, which is affected by the beginning inventory and the end inventory. JMETI (2007) suggests calculating inter-process integration factors by the positive standard output of the last quantity center and multiplying this by costs and inter-process integration factors. Doing this allows us to obtain the values transferred in which match the values transferred out from the previous quantity center.
} 


\section{Macrothink}

Asian Journal of Finance \& Accounting

ISSN 1946-052X

2015, Vol. 7, No. 1

Table 2. Costing Table of Input/ Output after Balanced Adjustment (Standard Output is $1,000,000 \mathrm{~kg})$

\begin{tabular}{llcccc}
\hline & & Drawing & Spheroidizing & Phosphating & Continuous Drawing \\
\hline \multirow{2}{*}{ Current } & Materials cost & $25,752,656$ & 35,060 & 266,291 & 204,609 \\
new input & System cost & 317,373 & 136,267 & 266,004 & 199,475 \\
& Energy cost & 172,512 & 547,144 & 105,552 & 54,241 \\
\hline \multirow{2}{*}{ Brought } & Materials cost & 0 & $25,138,480$ & $25,138,480$ & $25,049,479$ \\
\multirow{2}{*}{ down } & System cost & 0 & 310,145 & 442,999 & 684,619 \\
& Energy cost & 0 & 168,579 & 710,256 & 787,754 \\
\hline \multirow{2}{*}{ Total } & Materials cost & $25,752,656$ & $25,173,540$ & $25,404,772$ & $25,254,088$ \\
\multirow{2}{*}{ Positive costs } & System cost & 317,373 & 446,411 & 709,002 & 884,094 \\
costs & Energy cost & 172,512 & 715,723 & 815,808 & 841,995 \\
& Materials cost & $25,138,480$ & $25,138,480$ & $25,049,479$ & $25,113,300$ \\
\multirow{2}{*}{ Negative } & System cost & 310,145 & 442,999 & 684,619 & 879,237 \\
costs & Materials cost & 614,579 & 710,256 & 787,754 & 837,385 \\
& System cost & 7,229 & 35,060 & 355,293 & 140,788 \\
\hline \multirow{2}{*}{ Ther cost } & Energy cost & 3,933 & 3,413 & 24,383 & 4,857 \\
\hline
\end{tabular}

a. The above disclosed amount is based on the New Taiwan Dollar. The conversion rate for the US Dollar is 1:30.

\subsection{Improvements and Feedback}

The last step is improvements and feedback. The direction for improvement is primarily determined by analyzing positive and negative products. The analysis can be carried out based on physical information or monetary information, and the operating processes will be re-assessed according to the analysis results in order to determine the most urgently needed improvements in the operating processes. We will carry out MFCA after improvements are made, in order to understand the results and benefits of the improvements.

After calculating by MFCA, improvements and feedbacks are the most important factor. Our analysis results are summarized below.

\subsubsection{Water resources that companies are concerned with}

The waste of water resources is not as bad as was expected in either the positive or negative costs after calculation and analysis of water resources. Moreover, the costs are lower than expected, with an actual total cost of around $\$ 75,711^{9}$ per month, while the actual average negative cost is around $\$ 2,608^{10}$, as shown in Table 3 .

\footnotetext{
9 This value is the mean for three months

10 This value is the mean for three months.
} 
Table 3. Water Resources Costs for the Phosphating Process Center

\begin{tabular}{lccc}
\hline & October & November & December \\
\hline $\begin{array}{l}\text { Water resources costs } \\
\begin{array}{l}\text { Negative proportions in } \\
\text { the phosphating process } \\
\text { center }\end{array}\end{array}$ & $\$ 79,347.62$ & $\$ 75,017.31$ & $\$ 72,767.63$ \\
\hline $\begin{array}{l}\text { Negative costs for water } \\
\text { resources }\end{array}$ & $\$ 2,991.41$ & 0.0327 & 0.0327 \\
\hline $\begin{array}{l}\text { Inter-process integration } \\
\text { factors }\end{array}$ & 0.396869332 & 0.424951704 & 0.399282138 \\
\hline $\begin{array}{l}\text { Negative costs for } \\
\text { generating 1,000,000kg of } \\
\text { water resources }\end{array}$ & $\$ 1,187.20$ & $\$ 1,042.44$ & $\$ 950.09$ \\
\hline $\begin{array}{l}\text { Total negative costs for } \\
\text { generating 1,000,000kg of } \\
\text { water resources (in the } \\
\text { phosphating process } \\
\text { center) }\end{array}$ & $\$ 397,060$ & $\$ 400,736$ & $\$ 425,394$ \\
$\begin{array}{l}\text { Proportion of total } \\
\text { negative costs for water } \\
\text { resources in the total } \\
\text { negative costs }\end{array}$ & 0.00299 & & \\
\hline $\begin{array}{l}\text { a. The above disclosed amount is based on the New Taiwan Dollar. The conversion rate for the US } \\
\text { Dollar is 1:30. }\end{array}$ & & & \\
\hline
\end{tabular}

In fact, the rate of water reclamation of the case company reaches almost $70 \%$, so there is little room for improvement with limited benefits. The benefits could be even greater if it is no longer necessary to handle the sewage through the company's sewage treatment equipment, instead sending these emissions to the sewage treatment plant. In terms of environmental protection and MFCA, it is possible to achieve the goals in terms of both economy and environmental protection by making the best of ones resources. In order to provide the authorities with investment decisions concerning water conservation, we assume that the recyclability rate can reach $90 \%$ with certain reclamation equipment. In other words, only $10 \%$ of the original water resources are wasted. Provided that the life of the equipment is 10 years with a discount rate of $6 \%, 8 \%$ and $10 \%$, the results are shown in Table 4 below. Under a discount rate of $10 \%(8 \%, 6 \%)$, it is worth investing if the investment costs are under $\$ 851,030$ (\$929,352, $\$ 1,019,378)$. That is, if investment costs are lower than investment cost limitations in the three situations, then such an investment can reduce costs and be environmental friendly ${ }^{11}$. We assessed that the reverse osmosis (RO) technique can increase the recyclability of water with an establishment charge of around $\$ 600,000$ in total. This conforms to the investment limitation set out in this paper, and so we suggest that the company establish a water reclamation system.

\footnotetext{
${ }^{11}$ This analysis only focuses on the expenses of water resources without considering the costs saved in the sewage treatment of company and industrial areas, or the income tax saved in depreciation.
} 
Table 4. Investment Costs Limitation for Water Resources

\begin{tabular}{l|c|c|c}
\hline & $6 \%$ discount rate & $8 \%$ discount rate & $10 \%$ discount rate \\
\hline $\begin{array}{c}\text { Amount saved for } \\
\text { water resources } \\
\text { (year) }\end{array}$ & $\$ 138,501$ & $\$ 138,501$ & $\$ 138,501$ \\
\hline $\begin{array}{c}10 \text { years, present } \\
\text { value of annuity }\end{array}$ & 7.3601 & 6.7101 & 6.1446 \\
\hline $\begin{array}{l}\text { Investment costs } \\
\text { limitation }\end{array}$ & $\$ 1,019,378$ & $\$ 929,352$ & $\$ 851,030$ \\
\hline
\end{tabular}

a. The above disclosed amount is based on the New Taiwan Dollar. The conversion rate for the US Dollar is $1: 30$.

\subsubsection{Analysis of negative costs}

This paper discovers that the drawing process center, phosphating process center and continuous drawing process center generate most of the company's waste. Table 5 presents the data on relevant negative costs ${ }^{13}$. The material negative costs for each quantity center reach $80 \%$ of the total negative costs. The drawing process center has the greatest material negative costs in terms of wastage, and the continuous drawing process center comes in second. In terms of materials, the phosphating process center has the greatest negative costs. The case company should initiate improvements in the drawing process center or the continuous drawing process center in order to reduce material costs, because this will bring greater benefits, instead of making decisions based on subjective judgments.

The reason why negative costs exist in the drawing process center and the continuous drawing process center is defective products. These products account for a high proportion of the negative costs, so reducing defective products should be considered a viable starting point. The case company should pay attention to the reasons for defective products and set up checkpoints in the spheroidizing process center in order to prevent these products from entering the phosphating process center and the continuous drawing process center, which increases the remaking costs. The large amount of material costs used in the phosphating process center may not be improved in the short term because it is restricted by the operating process and the scale of existing equipment. If plant expansion is required in the future, the company can consider the equipment type and scale of the phosphating process center when purchasing, in order to enhance the utilization of materials and thereby reduce negative costs.

\footnotetext{
12 The water emissions originally made up $30 \%$ of total usage. Assume that the utilization of water resources increases and that the emissions rate is reduced to $10 \%$. This would equal the saved costs multiplied by the unit costs without considering water reclamation by equipment (except for the weekly water change of the third sink in the phosphating process). The calculation values are the saved water costs in October, November and December.

${ }^{13}$ Waste disposal costs are not included.
} 
Table 5. Table of Material Negative Costs (Standard Output is $1,000,000 \mathrm{~kg}$ )

\begin{tabular}{l|c|c|c|c}
\hline & Drawing & Spheroidizing & Phosphating & $\begin{array}{c}\text { Continuous } \\
\text { Drawing }\end{array}$ \\
\hline $\begin{array}{l}\text { Material negative } \\
\text { costs (A) }\end{array}$ & $\$ 614,176$ & $\$ 35,060$ & $\$ 355,293$ & $\$ 140,788$ \\
\hline $\begin{array}{l}\text { Total negative } \\
\text { costs (B) }\end{array}$ & $\$ 625,337$ & $\$ 43,940$ & $\$ 407,730$ & $\$ 150,256$ \\
\hline Proportion (A/B) & 0.9821 & 0.7982 & 0.8710 & 0.9372 \\
\hline
\end{tabular}

a. The above disclosed amount is based on the New Taiwan Dollar. The conversion rate for the US Dollar is 1:30.

\subsubsection{Analysis of relative indices}

Although it is simple to understand the room for improvements in terms of total amounts, relative indices are also crucial. Relative indices provide comparisons among companies and months, and also indicate critical points which absolute indices do not. Table 6 shows the accumulated costs of each process center, which allows us to understand the significance and severity of remake costs.

After processing in the drawing process center, the case company immediately performs an inspection. Defective products are remade in the drawing process center. Raw materials can be recycled and reinvested, so that positive costs of finished goods per kilogram will increase from $\$ 25.5915$ to $\$ 26.0697^{14}$. This means a cost increase of $1.87 \%$. Before delivering the products to customers (i.e. after manufacturing in the continuous drawing process center), the company performs another inspection to judge whether the products meet customers' requirements. Defective products caused by stiffness, toughness, hardness and consistency will be remade in the drawing process center and then recast in the spheroidizing process center. These products need to be cleaned in the phosphating process center and processed again in the continuous drawing process center. The cost of positive products per kilogram increases from $\$ 26.8299$ to $\$ 28.5465$, with a cost increase of $6.4 \%$. In terms of material processing, the system costs and energy costs of disqualified goods are double those of finished goods after deducting raw material costs.

Table 6. Table of Accumulated Costs of Positive Products Costs in Process Centers (Per kg)

\begin{tabular}{|c|c|c|c|c|}
\hline & Drawing & Spheroidizing & Phosphating & $\begin{array}{c}\text { Continuous } \\
\text { Drawing }\end{array}$ \\
\hline Material costs & $\$ 25.1133^{15}$ & $\$ 25.1133$ & $\$ 25.1133$ & $\$ 25.1133$ \\
\hline System costs & $\$ 0.3098$ & $\$ 0.4425$ & $\$ 0.6863$ & $\$ 0.8792$ \\
\hline Energy costs & $\$ 0.1684$ & $\$ 0.7095$ & $\$ 0.7897$ & $\$ 0.8374$ \\
\hline Total costs & $\$ 25.5915$ & $\$ 26.2654$ & $\$ 26.5893$ & $\$ 26.8299$ \\
\hline
\end{tabular}

The above analysis indicates that the continuous drawing process center has serious remake

\footnotetext{
$1426.0697=25.5915+0.3098+0.1684$

15 Refers to raw material costs. Other materials are transferred to negative products.
} 
problems in terms of defective products. If the company can identify defective products at an earlier stage and remake them immediately, then it should reduce the remake costs of these products. Hence, this paper suggests that setting up checkpoints after the spheroidizing process center can contribute to discovering and resolving problems in a timely manner and preventing the doubling of system costs and energy costs in the phosphating process center and the continuous drawing process center. Besides, there are two further points to consider when setting up checkpoints:

1. Compare the establishment costs and expected benefits of checkpoints to determine its feasibility.

\section{Maintain system efficiency.}

However, in terms of cost benefits, without considering extra expenditure, the company may move the inspection of products' stiffness, toughness, hardness and consistency in the continuous drawing process center forward to the spheroidizing process center in order to solve problems. The company can further decide if there are any improvements, such as update of techniques and elimination of old equipment, which can reduce the quantity of defective products to zero. This can actually help the case company to mitigate certain costs. Last but not least, MFCA can be seen as a judgment tool for an improvement approach. The company should implement the improvements and verify whether the results are as expected, by carrying out MFCA so as to enhance productivity and save costs. Until then, a complete cycle of MFCA is finished.

Aside from an analysis of costs for positive units, it is also important to analyze the total amount of positive costs. Since inter-process integration factors are applied, the basic calculation for the continuous drawing process center each month is $1,000,000 \mathrm{~kg}$. A cost comparison for each month is very useful. As shown in Table 7, the positive unit cost is around $\$ 26.8$ each month. This cost can be combined with a standard costing system when the study period is longer, in order to carry out cost control or an analysis of cost variance. In other words, we will know if there is a tremendous increase or decrease in positive costs for particular units in a certain month, so that the manager can react quickly to reduce potential losses.

Table 7. Comparison of Positive Unit Costs in Each Month (Unit: per kg)

\begin{tabular}{lccc}
\hline & Oct & Nov & Dec \\
\hline Total cost & $\$ 26,855,216$ & $\$ 26,857,170$ & $\$ 26,777,378$ \\
\hline Theoretical yield & $1,000,000$ & $1,000,000$ & $1,000,000$ \\
\hline Cost per unit & $\$ 26.8552$ & $\$ 26.8572$ & $\$ 26.7774$ \\
\hline $\begin{array}{l}\text { a. The above disclosed amount is based on the New Taiwan Dollar. The conversion rate for the US } \\
\text { Dollar is } 1: 30 \text {. } \\
\text { b. Total cost= material cost }+ \text { system cost }+ \text { energy cost }\end{array}$ & & \\
\hline
\end{tabular}

\subsubsection{Waste heat and residue recovery management}

A considerable amount of waste heat is generated in the spheroidizing process center without being recycling or reused. The residue generated in the phosphating process center can be 
handled through a drying process in order to reduce disposal fees. This paper suggests that the company should purchase waste heat recovery equipment in order to handle the drying process of residue. The equipment costs around $\$ 1,500,000$ to $\$ 2,000,000$ whereas the contract price for residue disposal is $\$ 55,000$ per month. Based on a cost recovery method, it only takes around 3 years to recover the cost of purchasing waste heat recovery equipment (without considering the income tax saved due to depreciation of equipment) with a relatively high return on investment.

\section{Conclusion and Suggestions}

Corporate environmental responsibility should be first considered as the pivotal activity in implementing an environmentally oriented strategy in business, and thereby, as the source of competitive advantage (Lee, 2012; Ulubeyli, 2013). MFCA has gained more attention recently because it not only values physical information, but also combines physical and monetary data to calculate costs on a consistent basis. With the management and control of waste and defective products, the system discloses relevant physical and monetary information for managerial decision making. The main purpose of this paper is to prove the feasibility and usefulness of MFCA. This paper uses a small- or medium-size enterprise in the metal processing industry as our object of study. This study has shown that the establishment of MFCA, and the analysis of costs and waste and information generated by MFCA, can assist senior managers to mitigate the probability of dysfunctional decision making. For corporations, traditional costing systems or activity-based costing systems emphasize amortizing manufacturing overhead. Since direct raw materials and direct labor are directly attributed to the cost objects, management believes that losses are normal; however, this can be avoided from the MFCA perspective. Moreover, MFCA attaches importance to physical information which has previously been ignored by management.

Before implementing MFCA, the case company believed that the waste came from water resources, which allowed for more room for improvement. According to the implementation results, the waste of water and materials, as well as sewage treatment, are indeed key areas for improvement. Furthermore, the case company did not set up any information about defective products nor any appropriate control on these products because the manager thought that they could be remade. The results have proved that unit product costs increased by $100 \%$ for remaking defective products, without considering raw material costs. Hence, the case company should improve the usage and waste of materials. This paper also suggests setting up checkpoints in the spheroidizing process center in order to immediately discover any defective products and thereby avoid ineffective inputs. The checkpoints can be moved from the continuous drawing process center in order to save extra costs and solve the problems encountered by the company. We also suggest upgrading techniques and eliminating old equipment in the phosphating process center in order to reduce negative costs if technology allows.

Key success factors for the implementation are the collection of data and communication with the staff. The degree of data collection is closely related to the costs because enterprises may refuse or be unable to establish MFCA for cost benefit- related issues. We needed the 
support of the accountants to provide the data needed. We were also supported by the operators, accountants, general manager and vice general manager during implementation. We looked for solutions to problems identified during discussions with management. The implementation might have failed if we did not have the support of management and the data provided by the accountants.

The implementation of MFCA also proved that it is both feasible and useful. The system highlights the significance of direct raw materials and materials that are normally ignored; at the same time, it helps management to find out which processes need improvements to avoid dysfunctional decisions. Moreover, products and wastage are discussed on the same basis, so that wastage will not be ignored because it is thought to have no value. In the past, there was no direct connection between physical and monetary data because they were only linked in an indirect way. With MFCA, which calculates monetary data on the basis of physical data, both data can be directly linked so that the information provided is more accurate and helpful to management in decision making and output control.

Finally, the case company can divide their major operations (e.g. the phosphating process center) to create a detailed quantity center in order to explore the utilization of materials, waste management or water resources costs if more detailed information is needed in the future. Further studies can pay attention to the assessment of environmental management accounting tools instead of only to the discussion of MFCA, although it is the most significant. We suggest that future studies carry out case analyses and research to explore the strengths and weaknesses of each tool and its applicability. The application of MFCA may be suitable in Taiwan because most industries are manufacturing industries or OEM. Future studies can discuss whether the establishment steps proposed in this paper are suitable for other process manufacturing industries or other industries in general.

\section{References}

Brunner, P.H. \& Rechberger., H. (2005). Practical Handbook of Material Flow Analysis, Lewis Publishers.

Chen, C.T. \& Ko, C.F. (2005). Accounting Information Systems (fifth). Shinlou, Taiwan.

Chetty, S. (1996). The case study method for research in small-and medium-sized firms. International Small Business Journal, 15-85. http://dx.doi.org/10.1177/0266242696151005

Djajadikerta, H. G. \& Trireksani, T. (2012). Corporate social and environmental disclosure by Indonesian listed companies on their corporate web sites, Journal of Applied Accounting Research, 13(1), 21-36. http://dx.doi.org/10.1108/09675421211231899

Elliot, S. (2011). Transdisciplinary perspectives on environmental sustainability: a resource base and framework for IT-enabled business transformation. MIS Quarterly, 35(1), 197-236.

European Communities (2001). Economy-wide material flow accounts and derived indicators -A methodological guide.

Fakoya, M.B. \& van der Poll, H.M. (2013). Integrating ERP and MFCA systems for improved waste-reduction decisions in a brewery in South Africa. Journal of Cleaner 
Production, 40, 136-140. http://dx.doi.org/10.1016/j.jclepro.2012.09.013

Green Jr, K.W., Zelbst, P. J., Bhadauria, V.S. \& Meacham, J. (2012). Do environmental collaboration and monitoring enhance organizational performance? Industrial Management \& Data Systems, 112(2), 186-205. http://dx.doi.org/10.1108/02635571211204254

Hargroves, K. J. \& Smith, M. H. (2012). The Natural Advantage of Nations: Business Opportunities, Innovations and Governance in the 21 st Century. CRC Press, London.

IFAC International Federation of Accountants. (2005), Environmental Management Accounting- International Guidance Document.

ISO 14051, (2011). Environmental management - Material flow cost accounting - General framework. International Organization for Standardization.

Lee, L.T.S. (2012). The pivotal roles of corporate environment responsibility. Industrial $\begin{array}{lllll}\text { Management } \& \text { Data Systems, } & 112(3), & 466-483 .\end{array}$ http://dx.doi.org/10.1108/02635571211210077

Leo'n-Soriano, R., Muñoz-Torres, M. \& Chalmeta-Rosalen, R. (2010). Methodology for sustainability strategic planning and management. Industrial Management \& Data Systems, 110(2), 249-68. http://dx.doi.org/10.1108/02635571011020331

METI Ministry of Economy, Trade and Industry, (2007). Guide for Material Flow Cost Accounting (Ver.1). Environmental Industries Office, Environmental Policy Division Industrial Science and Technology Policy and Environment Bureau, Japan.

Möller, A. \& Prox, M. (2008). From Material Flow Cost Accounting to MFA and LCA, Proceedings of the 8th International Conference on EcoBalance, Tokyo.

Nakajima, M. (2004). On the differences between material flow cost accounting and traditional cost accounting. Kansai University Review of Business and Commerce, 6, 1-20.

Nakajima, M. (2006). The New Management Accounting Field Established by Material Flow Cost Accounting (MFCA). Kansai University Review of Business and Commerce, 8, 1-22.

Nakajima, M. (2009). Evolution of Material Flow Cost Accounting (MFCA): Characteristics on Development of MFCA Companies and Significance of Relevance of MFCA. Kansai University Review of Business and Commerce, 11, 27-4.6

Onishi, Y., Kokubu, K. \& Nakajima, M. (2009). Implementing material flow cost accounting in a pharmaceutical company. In: Schaltegger, S., Bennett, M., Burritt, R.L., Jasch, C. (Eds.), Environmental Management Accounting for Cleaner Production. Springer, Netherlands, pp.395-409.

Serdar Ulubeyli, (2013). Drivers of environmental performance of cement plants. Industrial $\begin{array}{lllll}\text { Management } \quad \text { D } \quad \text { Data } \quad \text { Systems, } & 113(8), & 1222-1244 .\end{array}$ http://dx.doi.org/10.1108/IMDS-01-2013-0007

Stacks, D.W. (2010), Primer of Public Relations Research, second ed. The Guilford Press, New York.

Sulong, F., Sulaiman, M., \& Norhayati, M. A. (2014). Material Flow Cost Accounting (MFCA) Enablers and Barriers: The Case of a Malaysian Small and Medium-sized Enterprise (SME). Journal of Cleaner Production, http://dx.doi.org/10.1016/j.jclepro.2014.08.038 